\title{
O surgimento do PSD e o sistema partidário brasileiro'
}

\author{
Sergio Simoni $\mathbf{r}^{2}$ \\ Ricardo Mendes Ribeiro ${ }^{3}$
}

\section{Resumo}

O que explica a volta do fenômeno de formação de novos partidos relevantes no Brasil? Como isto se relaciona com a institucionalização do sistema partidário ou a estrutura da competição? Avançamos nessa discussão a partir da análise do Partido Social Democrata (PSD). Reconstituímos seu processo de formação, sublinhando atores, estratégias e conjunturas; analisamos o comportamento legislativo na Câmara dos Deputados dos parlamentares que migraram para o partido e exploramos seu desempenho eleitoral em 2012 e 2014, ressaltando lançamento de candidaturas e o perfil local de votação no partido. Chamamos atenção para o fato de que a estrutura da competição partidária federal e local conferem lógica aos fenômenos analisados. Além disso, defendemos que são centrais para entender a formação e força do PSD, e dos demais novos partidos, as decisões e interpretações do Poder Judiciário sobre as leis partidário-eleitorais, elemento não previsto nas teorias comparadas de formação de novos partidos.

Palavras-chave: Partidos políticos. Institucionalização do sistema partidário. Novos partidos. Sistema de partido multinível.

\section{Introdução}

Em texto de balanço após a eleição de 2014, Avelino (2015) sentenciou: "Brasil, o maior NEP [Número efetivo de partidos] do mundo!".

\footnotetext{
I Agradecemos os comentários de Bruno Bolognesi e demais participantes do III Fórum Brasileiro de Pós-Graduação em Ciência Política a uma versão anterior do trabalho, e a Joyce Luz pelo acesso aos dados legislativos. Sergio Simoni Junior agradece ainda a bolsa de pós-doutorado conferida pelo INCT "Instituto da Democracia e da Democratização da comunicação", no âmbito do CESOP/UNICAMP.

2 Professor do Programa de Políticas Públicas e do Programa de Ciência Política da UFRGS. E-mail: sergiojr_ssj@ yahoo.com.br

3 Doutor em Ciência Política pelo DCP-USP. Analista político MCM Consultores. E-mail: ricardomribeiro@uol. com.br
}

\section{$(\infty))$ EY}

Direito autoral e licença de uso: Este artigo está licenciado sob uma Licença Creative Commons. Com essa licença você pode compartilhar, adaptar, para qualquer fim, desde que atribua a autoria da obra, forneça um link para a licença, e indicar se foram feitas alterações. 
Essa percepção não é recente. Há cerca de 25 anos, o famoso brasilianista Thomas Skidmore declarou, em uma entrevista, que "o sistema partidário [brasileiro é] o mais fragmentado de qualquer democracia no mundo" (NICOLAU; SCHIMITT, 1995, p. 129).

Esse diagnóstico, muitas vezes inserido em uma discussão maior sobre institucionalização do sistema partidário, é um dos principais temas de pesquisa da Ciência Política brasileira (NICOLAU, 2010). Diversos trabalhos defendem que os partidos nacionais são pouco institucionalizados, têm ideologia fluida e não possuem sólidas raízes societárias (MAINWARING, 1999; MAINWARING; TORCAL, 2005; KINZO, 2004). Alguns mecanismos institucionais são apontados como causas desse cenário, notadamente: o sistema eleitoral de lista aberta com magnitude elevada, a possibilidade de coligaçóes eleitorais, e, pontos que nos interessam sobremaneira neste texto, a migração partidária (de magnitude elevada até 2007, antes de sofrer regulamentaçóes do Poder Judiciário), e o federalismo robusto, que fortalece a arena local.

Um conjunto de trabalhos, ainda que com assertividades diferentes, tem defendido uma visão alternativa (LIMONGI; CORTEZ, 2010; MELO, 2010; MELO; CÂMARA, 2012; BRAGA, 2010; CORTEZ, 2009; LIMONGI; VASSELAI, 2018). Para esses autores, o sistema partidário teria uma lógica de funcionamento "simples e inteligível" (LIMONGI; CORTEZ, 2010, p. 22). Ressaltam que, embora a fragmentação impere nas eleiçóes legislativas proporcionais, nas disputas majoritárias - as mais importantes para os políticos e para os eleitores -, observa-se uma concentração em poucas legendas. Nos pleitos presidenciais, a proeminência do Partido dos Trabalhadores (PT) e do Partido da Social Democracia Brasileira (PSDB) é clara de 1994 a 2014. Alguns desses autores argumentam que esses partidos replicariam sua hegemonia também nas disputas estaduais.

Dentro dessa linha de argumentação, Melo e Câmara (2012) ressaltam que a saída de várias legendas do jogo presidencial e mesmo nos pleitos para governador não implicaria sua irrelevância no sistema político, pois, no presidencialismo de coalizão multipartidário, bancadas legislativas representam um importante ativo de poder. Assim, algumas legendas traçariam estratégias de modo a maximizar sua força nesta arena. 
O quadro de estabilidade proposto por esses autores não ficou imune a críticas. Carreirão (2014), por exemplo, apresenta uma posição contrária. Dentre outros argumentos, o autor destaca que "[...] a criação do PSD [...] parece mostrar que aquela tendência à estabilidade talvez não tenha sido tão duradoura" (CARREIRÃO, 2014, p. 265). É a partir desse ponto que este trabalho se desenvolve.

De fato, após 2011, assiste-se ao retorno da formação da formação de novos partidos relevantes. Dentre estes, destaca-se o Partido Social Democrático (PSD) ${ }^{4}$, que, no momento da formação, atraiu cerca de $10 \%$ da Câmara dos Deputados (tornando-se o terceiro maior partido na Câmara dos Deputados, abaixo de PT e PMDB), dois governadores, dois senadores e seis vice-governadores (em São Paulo, Bahia, Mato Grosso, Rio Grande do Norte, Paraíba, Tocantins).

Como explicar esse fenômeno? Novas clivagens surgiram na política brasileira; choques externos abalaram o sistema; uma reforma política foi aprovada? Afinal, o sistema partidário brasileiro não teria uma estrutura organizadora?

Apresentamos dois principais argumentos neste texto. $\mathrm{O}$ primeiro é que, antes de demonstrar sua inadequação, o processo de formação do PSD pode ser explicado precisamente pela tese da estrutura da competição, embora demandando refinamentos analíticos. $\mathrm{O}$ cerne do processo político de formação do partido diz respeito a movimentaçóes da elite política em busca de maximizar sua força congressual e local. Generalizando, defendemos que o retorno da relevância do processo de criação de novos partidos é compreensível no bojo da interdição à migração partidária. E, como demonstraram os estudos sobre a lógica deste fenômeno, deve ser analisada dentro de uma perspectiva multinível, ou seja, de uma determinação recíproca entre os níveis nacionais e locais do sistema partidário.

O nosso segundo argumento busca contribuir para as teorias de formação de novos partidos. Argumentamos que uma das principais variáveis que influenciaram a formação e a força do PSD foram decisóes do Poder

4 O Partido Republicano da Ordem Social (PROS) e o Solidariedade (SD) são outros partidos novos relevantes que, acreditamos, também podem ser explicados segundo a lógica exposta neste artigo. 
Judiciário. É uma variável que não decorre de alteração explícita de regras, seja da Constituição ou da legislação partidária ou eleitoral. É resultado de entendimentos e interpretaçôes do Judiciário sobre as regras vigentes.

Apresentamos neste artigo uma "narrativa analítica" (BATES et al., 1998) da formação do PSD. Do ponto de vista qualitativo, narramos seu surgimento a partir de dissensóes internas do DEM, bem como as decisões judiciais que incentivaram e fortaleceram esse movimento. Do ponto de vista quantitativo, apresentamos dados sobre os partidos e estados de origem do grupo de deputados federais fundadores do PSD, e também seu grau de apoio ao governo em votaçôes na Câmara dos Deputados. Outra vertente de investigação empírica consiste na análise do lançamento de candidaturas, no padrão de coligaçóes e de desempenho eleitoral em 2012 e 2014.

A formação do PSD e, extrapolando, de outros novos partidos relevantes, não pode ser tida simplesmente como uma expressão da fragilidade do sistema partidário brasileiro, nem como um movimento em direçáo à coalizão governante. Tal processo, a nosso ver, deve ser compreendido como um mecanismo de ajuste entre forças políticas nacionais e locais inseridas em um sistema de competição aninhado, mas extremamente complexo, com diversos níveis federativos e regras eleitorais.

$\mathrm{O}$ artigo segue da seguinte forma: na próxima seção, apresentamos a discussão sobre o sistema partidário brasileiro e sua lógica de funcionamento, chamando atenção para o fenômeno da migração partidária e para as teses recentes sobre estrutura da competiçáo; em seguida, apresentamos a literatura teórica sobre formação de novos partidos, ressaltando, de um lado, como o PSD não se enquadra nas principais explicações, e de outro, como o estudo deste caso pode contribuir para avançar os modelos vigentes; a análise empírica, que vem adiante, consiste na apresentação de uma narrativa da formação do partido a partir de dissidências do DEM; para, depois, ser feita uma análise quantitativa do comportamento parlamentar e do desempenho do PSD nas eleiçôes de 2012 e 2014. Nas conclusôes finais, apresentamos uma recapitulação do artigo. 


\section{Arcabouço teórico}

\section{Estrutura do sistema partidário brasileiro}

Tradicionalmente, o sistema partidário brasileiro é considerado pouco ou nada institucionalizado, e a fragmentação partidária seria uma das evidências desse fenômeno. Parte do número excessivo de partidos foi causada pela troca de partidos por parlamentares, conhecida como migração partidária. Melo (2000) calculou que cerca de 30\% dos deputados federais mudaram de partido ao menos uma vez entre 1982 a 1998. Qual é a explicação para esse fenômeno?

A literatura costuma destacar que esse comportamento é decorrente de decisões estratégicas do político que busca maximizar sua força política e eleitoral. As variaçóes observadas são fruto de diferentes constrangimentos a depender do partido de origem, do estado da federação e da base eleitoral do parlamentar (MELO, 2000; DESPOSATO, 2006). Um mecanismo explicativo em particular para o fenômeno da migração interessa ao presente artigo. Trata-se da competição eleitoral estadual. Como se sabe, os deputados federais no Brasil são eleitos em distritos estaduais. Freitas (2012) sugere que as migraçôes são resultado das dissonâncias entre as forças partidárias estaduais de cada parlamentar e as forças partidárias nacionais, levantando a hipótese de que a migração pode ser uma estratégia conjunta de parlamentares e partidos para se fortalecerem nos diferentes estados.

Ou seja, ao invés de ser um fenômeno errático, não padronizado e debilitador do sistema partidário, a migração de parlamentares consistiria em uma instância adicional da competição entre os partidos, regida pela relação entre os níveis nacional e local do sistema federativo brasileiro.

Parte da literatura generaliza essa posição e afirma que o sistema partidário brasileiro apresenta uma estrutura de competiçáo e mecanismos de coordenação que passam pela dinâmica nacional-local (CORTEZ, 2009; LIMONGI; CORTEZ, 2010; MELO, 2010). Esses autores argumentam que a lógica da estabilidade da disputa presidencial entre PSDB e PT (até 2014) encontra na estrutura da competiçáo nos estados um elemento crucial: esses partidos coordenam com seus aliados a participação nas disputas 
para governador, aninhando-as com o pleito para presidente. Em contraste com a fragmentação do Congresso, esse mecanismo implicaria concentração partidária nos pleitos majoritários.

Essa linha de argumentação condiz com uma abordagem em ascensão na literatura comparada, a qual defende a importância de análises multiníveis para a compreensão dos sistemas partidários (DOSEK; FREIDENBERG, 2013; CHHIBBER; KOLLMAN, 2004; LAGO; MONTERO, 2009). O ponto consiste em apontar a insuficiência de análises focadas apenas na dinâmica do nível central do Estado, ressaltando a necessidade de considerar o quadro partidário no plano local, bem como a relação de influência mútua que se estabelece entre os níveis.

Em termos gerais, de acordo com essa visão, os partidos devem ser analisados como organizaçóes formadas e modeladas de modo a atender aos interesses dos políticos, dados os constrangimentos institucionais (ALDRICH, 1995). A partir do trabalho de Samuels e Shugart (2016), que ressaltam a importância dos incentivos gerados pelo sistema de governo para a estrutura partidária, consideramos que, no caso do presidencialismo de coalizão brasileiro, ocorre uma espécie de "divisão do trabalho": partidos com "vocação executiva" se organizam e lançam mão de determinadas estratégias diversas das adotadas pelas legendas que buscam maximizar suas bancadas legislativas.

Nesse sentido, neste artigo, argumentamos que uma explicação adequada do processo de criação do PSD deve conter elementos tanto do nível nacional e do nível local do sistema político brasileiro quanto levar em consideração a estrutura da competição partidária em um sistema presidencialista multipartidário. Refinando visóes correntes, nossas evidências mostram que devemos levar a sério a análise multinível: ao invés de uma determinação unidirecional do nacional sobre o local, ou do local sobre o nacional, afirmamos que existem importantes relaçôes recíprocas entre os níveis.

Quanto à estrutura do sistema do partidário, sublinhamos a afirmação de Melo e Câmara (2012) de que "[...] tomar como prioritária [...] a eleição de boas bancadas no Congresso não implica uma saída do jogo presidencial" (MELO; CÂMARA, 2012, p. 84). Os autores se referem 
especificamente a um grupo de partidos (PMDB, PP, PTB e PR) que, mesmo não participando do pleito nacional, ainda assim se mantêm relevantes para o funcionamento do presidencialismo de coalizão. $\mathrm{Ou}$ seja, embora ocorra uma disputa em distritos estaduais, as eleiçóes para o Congresso têm implicaçôes para o funcionamento do sistema político nacional. Os autores denominam esse grupo de partidos "disponíveis", pois eles não teriam restriçôes a se aliar a qualquer dos dois polos que lideram as disputas presidenciais: o bloco PT-PSB-PCdoB-PDT e o bloco PSDB-DEM-PPS.

Nessa tipologia, entendemos que o PSD se soma ao grupo de partidos "disponíveis". Um episódio corrobora a inclusão do PSD nesse grupo. Em maio de 2013, um de seus mais importantes quadros, Guilherme Afif Domingos, assumiu a Secretaria da Micro e Pequena Empresa, sem abrir mão do cargo de vice-governador de São Paulo, estado-fortaleza, por assim dizer, do PSDB, que o governa desde 1995. Ou seja, o PSD se manteve próximo tanto do PT quanto do PSDB.

\section{Teorias de formação de novos partidos}

Existem muitas teorias e hipóteses sobre formação e força de novos partidos. De modo geral, elas ressaltam a importância do surgimento de novas clivagens, de choques externos ao sistema partidário, e de mudanças deliberadas de regras institucionais. No entanto, argumentamos que elas são insuficientes para compreender o processo de formação do PSD. Seguimos o caminho apontado por Marchetti (2008) acerca do modelo de governança eleitoral do caso brasileiro, e apontamos que as interpretaçóes do Poder Judiciário sobre a legislação partidária e eleitoral incentivaram e fortaleceram o PSD.

Com o exercício contínuo da competição eleitoral, espera-se o surgimento de um equilíbrio entre o mercado eleitoral e a capacidade de os partidos existentes atenderem às diferenciadas demandas desse mercado (COX, 1997). Se o sistema partidário está consolidado, o custo esperado de entrada no sistema partidário deveria superar o benefício esperado de vencer eleiçóes e obter cargos. Nessa situação, novos partidos, quando formados, tendem a ser irrelevantes no sistema político. 
No entanto, mesmo em democracias antigas, com sistemas partidários vistos como consolidados, novos partidos surgem, e alguns deles ganham relativa expressão. $\mathrm{O}$ equilíbrio pode ser quebrado quando um novo issue ganha importância política e os partidos já existentes não estão preparados para lidar com ele (HARMEL; ROBERTSON, 1985). Lago e Martínez (2011, p. 7) relacionam o surgimento de novos partidos a falhas do mercado eleitoral que ocorrem quando "significant number of individuals are left dissatisfied by the partisan choices available to them". Isso acontece quando os partidos ou candidatos existentes não conseguem ler corretamente as preferências do eleitor por desconhecimento ou por incapacidade de se adaptarem a mudanças sociais inesperadas que afetam as preferências. Um exemplo típico é o meio ambiente, que ganhou relevância a partir dos anos 1980 e favoreceu o surgimento de diversos partidos verdes mundo afora (POGUNTKE, 1987).

As instituições eleitorais são outra variável importante. Tavits (2006) e Hug (2000) indicam que partidos viáveis tendem a surgir com mais frequência quando o arcabouço institucional que regulamenta a criação de legendas é mais permissivo. A literatura aponta que sistemas proporcionais propiciam mais oportunidade a novos partidos (HARMEL; ROBERTSON, 1985). Além do arranjo do sistema eleitoral, os estudos também incorporam em conta o número de assinaturas requeridas para registro das legendas e a existência ou não de um fundo partidário público.

Chhibber e Kollman (2004), por sua vez, ao analisarem a nacionalização de partidos locais, concluem que, quanto menor o grau de centralização política e econômica, mais incentivos existem para que os partidos busquem se fortalecer no nível local, o que amplia oportunidades para novos partidos.

Nesse sentido, pode-se afirmar que a configuração do caso brasileiro é permeável ao surgimento de novos partidos viáveis. O sistema eleitoral proporcional com alta magnitude (MAINWARING, 1999), o federalismo robusto (SAMUELS, 2003), a exigência comparativamente pequena quanto ao número de assinaturas necessárias para registro de partidos (SU, 2015), a existência de fundo partidário público, além de taxas não elevadas de identificação partidária (CARREIRÃO; KINZO, 2004) e alta 
volatilidade (CARREIRÃO, 2014) concorreriam para estímulo à formação de novos competidores..

No entanto, mesmo nesse cenário propício, entre 2001 e 2010 apenas dois partidos relevantes se constituíram no Brasil - PSOL e PRB. O que explicaria o surgimento do PSD e demais novos partidos (como SD e PROS) depois desse período? Novas clivagens e issues surgiram no eleitorado? Ocorreram mudanças institucionais?

Defendemos que atos do Judiciário - portanto, mudanças institucionais oriundas de decisóes exógenas ao sistema partidário - foram essenciais para estímulo e o fortalecimento do PSD.

Marchetti (2008) argumenta que o arranjo da governança eleitoral brasileira implica considerável judicialização da competição partidária. A estrutura, o vínculo institucional e a composição do tribunal eleitoral possibilitam que as regras e as normas eleitoral-partidárias estejam sujeitas até mesmo a reinterpretaçóes de dispositivos constitucionais.

Para o presente caso, destacamos três decisóes do Judiciário, expostas com mais detalhes adiante. A primeira foi a regulamentação e a restrição à migração partidária, em 2007. A segunda e terceira dizem respeito à concessão ao PSD, em 2012, do Horário Gratuito de Propaganda Eleitoral (HGPE) e da quota do Fundo Partidário de acordo com sua bancada fundadora, apesar de o partido não ter participado da eleição de 2010 .

Assim, o PSD não constitui expressão de uma nova clivagem ou ideologia que demandaria representação. No entanto, antes que uma anomalia ou um fenômeno tipicamente brasileiro, cabe notar a análise de Sikk (2012), que argumenta que a maioria dos novos partidos em diversas democracias apresenta notável indistinção ideológica 5 . Contrário à ênfase excessiva na busca por explicação com base na ideologia, o autor aponta que apenas o qualificativo de "novo" pode ser suficiente para essas legendas atraírem votos.

5 Cabe lembrar a famosa declaração de Gilberto Kassab ao jornal O Estado de S. Paulo, em 29 de março de 201 I, a respeito da inclinação ideológica do PSD. Segundo Kassab, o PSD não seria "de direita, de esquerda, nem de centro". 
O caso do PSD pode contribuir teoricamente para essa literatura por ressaltar que um dos fatores que incentivam a formação de novos partidos são mudanças exógenas nas interpretaçôes das regras vigentes.

A partir da próxima seção, apresentamos a análise empírica do artigo. Iniciamos com uma narrativa do processo de formação do PSD.

\section{Análise empírica}

\section{Formação do PSD 6}

Para a compreensão qualitativa do processo de formação do PSD, cabe lançar mão de Panebianco (2005). Afinal, segundo o autor, para a dinâmica partidária, é essencial a disputa entre seus dirigentes com vistas ao domínio das "zonas de incerteza", que são as dimensões que estabelecem as linhas de autoridade dos partidos, como o saber especializado no manejo das relaçóes internas e externas do partido, o controle das regras organizativas, as fontes de financiamento e de recrutamento político etc.

Nesse sentido, o PSD é uma decorrência direta do fracasso do projeto de refundação do PFL, que culminou, em 2007, na troca do nome da legenda para Democratas, ou simplesmente DEM, como passou a ser conhecida. $^{7}$

A operação, cujo artífice principal foi o ex-senador Jorge Bornhausen, então presidente do partido, partiu da avaliação de que o PFL tendia a encolher após ter rumado para a oposição em consequência da eleição de Luiz Inácio Lula da Silva para a Presidência da República em 2002. Além da troca do nome, ocorreu também a ascensão de uma nova geração de políticos aos postos de comando do partido, processo estimulado pelos antigos dirigentes. Quando o PFL se transformou em DEM, Jorge Bornhausen cedeu a presidência do partido ao deputado federal Rodrigo Maia, então com 37 anos. Ao mesmo tempo, Gilberto Kassab assumiu a presidência do Conselho Político do partido, órgão concebido por Bornhausen

6 Parte da narrativa aqui exposta foi-nos relatada em entrevista concedida por Saulo Queiros, experiente político, fundador e um dos principais operadores do PSD.

7 Sobre a transformação do PFL em DEM, ver Ribeiro (2014). 
com poderes de decisão a respeito da formação de coligaçóes e indicação de candidatos a presidente e a vice-presidente da República.

A refundação do PFL, contudo, fracassou de maneira retumbante. A operação náo foi capaz de revitalizar o partido nem de impedir que continuasse a encolher em virtude do mau desempenho eleitoral e por causa do êxodo de políticos em direção, na maioria dos casos, a siglas próximas ao campo petista em nível federal.

Diante das previsíveis dificuldades que o DEM enfrentou na eleição de 2010, surgiram na imprensa especulaçóes a respeito da possibilidade de o DEM, ou de parte substancial do partido, se juntar a outra legenda. PSDB e PMDB eram os mais citados ${ }^{8}$. Começaram a aparecer também notícias a respeito de desentendimentos entre dois grupos importantes dentro do partido, um liderado por Gilberto Kassab e Jorge Bornhausen e outro pelos Maia: Rodrigo Maia, Cezar Maia e José Agripino Maia9. A causa primária da desavença, dizia a imprensa política, estava relacionada à disputa que se desenrolava no PSDB entre José Serra e Aécio Neves pela candidatura presidencial tucana em 2010. Os Maia preferiam Aécio Neves. Já Kassab e Bornhausen estavam mais alinhados a José Serra. Pouco depois do pleito, contudo, surgiram os primeiros sinais de que, mais do que preferências e afinidades políticas com ou outro candidato do PSDB, o que estava de fato em jogo no confronto entre os dois grupos era a disputa pelo controle do partido.

Passada a eleição, Gilberto Kassab acusou Rodrigo Maia de, sem consultar outros membros da cúpula partidária, ter alterado o estatuto do partido a fim de reduzir as atribuiçóes do Conselho Político, retirando-lhe o poder de decisão a respeito de candidaturas. A manobra executada por Rodrigo Maia passou a ser utilizada por Gilberto Kassab como argumento para justificar as desavenças entre os dois grupos.

Para os Maia, contudo, a razão principal da dissidência construída por Kassab era o desejo de se aproximar do governo Dilma entáo

8 Conforme publicado em O Estado de São Paulo, de 17 de novembro de 2010. https://acervo.estadao.com.br/ pagina/\#!/20 I0 1 I I 7-42764-nac-9-pol-a9-not.

9 Apesar do mesmo sobrenome, José Agripino não é parente de Rodrigo e Cezar Maia. 
recém-iniciado. A desavença em torno da alteração estatutária seria apenas uma desculpa para precipitar o racha. Em favor dessa interpretação a respeito da disputa do poder dentro do partido pesa o fato de que a limitação ao poder do Conselho Político ocorreu em dezembro de 2007. Não é crível que Kassab somente a tenha notado em 2010. Os conflitos entre os dois grupos ganharam intensidade crescente no começo de 2011. A eleição de Antônio Carlos Magalhães Neto para a liderança do DEM na Câmara dos Deputados em janeiro daquele ano, com apoio dos Maia, acentuou as rivalidades internas. Houve uma tentativa de acordo com base no encurtamento do mandato de Rodrigo Maia na presidência do DEM, o qual expirava em dezembro de 2011. Porém, não foi possível chegar a um nome de consenso entre os dois grupos. Kassab e seus aliados defendiam Kátia Abreu para a presidência do partido. Agripino Maia era o candidato do grupo rival e acabou sendo eleito em março de 2011 sem precisar enfrentar um concorrente, pois, ciente do favoritismo do senador potiguar, Kátia Abreu sequer oficializou sua candidatura. A essa altura, o grupo liderado por Kassab já estava decidido a deixar o DEM para criar um novo partido.

Os atritos internos que precipitaram a cisão do DEM transcorreram em um momento, em 2010 e 2011, no qual o cenário de permanência do PT no poder para além de 2014 parecia bastante provável. Em primeiro lugar, porque a presidente Dilma Rousseff teria a possibilidade de disputar a reeleição em 2014 com boas chances de continuar no poder dada a vantagem que o incumbente, em condiçóes normais, dispóe frente à oposição. E, no caso de fracasso de sua administração, Dilma poderia ser substituída por Lula em 2014, que deixou a presidência com aprovação superior a $80 \%$, de acordo com pesquisas de opinião, como candidato presidencial petista.

Se Lula e o PT se fortaleceram, a oposição saiu mais combalida da disputa eleitoral. O PSDB enfrentou problemas parecidos aos do DEM, embora em escala menor. As bancadas do PSDB na Câmara dos Deputados e no Senado diminuíram em 2010 e a terceira derrota seguida do PSDB para o PT reativou as desavenças entre tucanos paulistas e mineiros.

Ainda no campo político, a ampla coligação que sustentou a candidatura Dilma formada por dez partidos - PT, PMDB, PSB, PDT, PR, 
PCdoB, PRB, PTN, PSC e PTC - indicava que a nova presidente disporia de expressivo apoio no Congresso, maior até do que o desfrutado por Fernando Henrique Cardoso e por Lula.

Condiçóes socioeconômicas também ajudaram a compor um ambiente favorável à aposta de que a hegemonia petista poderia durar bastante tempo. No plano econômico, a despeito da crise econômica internacional, a economia brasileira cresceu 7,5 em 2010. A ascensão da chamada nova classe média (NERI, 2010) somada ao alcance do programa Bolsa Família, que beneficiava mais de 11 milhóes de famílias de baixa renda, complementaram o quadro socioeconômico favorável à continuidade do PT no poder.

No entanto, como mostraremos nas próximas análises empíricas, não se pode sobredimensionar as movimentaçôes em direção ao governo federal petista nem as considerar como determinantes únicas para a formação do PSD. Outros elementos importantes se somaram para a constituição do partido.

\section{Legislação e Judiciário}

Ao redor do mundo, existem diversas formas de se organizar a governança eleitoral, entendendo por esse termo a responsabilidade pela definição das regras para a eleição, a administração do jogo partidário e do contencioso eleitoral. Marchetti (2008) ressalta que o caso brasileiro se destaca por conceder ênfase exclusiva a membros do Judiciário a administração do pleito e o contencioso eleitoral. Defendemos que decisóes emanadas do Judiciário incentivaram a formação do PSD e contribuíram para seu fortalecimento, impulsionando, assim, a formação de outros novos partidos.

Tida como uma das principais causas da fragmentação partidária no Brasil, a migração partidária foi objeto de decisão judicial em $2007^{10}$. Em março daquele ano, o TSE respondeu a uma consulta formulada pelo então PFL. O partido indagou: "Os partidos e coligaçóes têm o direito de preservar a vaga obtida pelo sistema eleitoral proporcional, quando houver pedido de cancelamento de filiação ou de transferência do candidato eleito

I0 Para um balanço da questão, consultar Silva e Santos (2013). 
por um partido para outra legenda?”. Por seis votos contra um, o tribunal respondeu afirmativamente.

A questão chegou ao STF por meio de mandatos de segurança. A Suprema Corte Brasileira revisou sua própria decisão tomada em 1989 e referendou a decisão do TSE, sacramentando o entendimento de que os mandatos eletivos de ocupantes de cargos do poder executivo ou parlamentares pertencem aos partidos ${ }^{11}$, incumbindo-o de emitir uma resolução regulamentado a questão.

Essa medida foi editada em outubro de $2007^{12}$, estabelecendo as condiçôes nas quais políticos poderiam mudar de partido sem ficar sujeitos à perda de mandato. De acordo com o $\$ 1^{\circ}$ do art. $1^{\circ}$ da Resolução, justas causas para migração partidária seriam a "[...] incorporação ou fusão do partido, a criação de novo partido, a mudança substancial ou o desvio reiterado do programa partidário vigente no momento da eleiçáo e a grave discriminação pessoal ocorrida no interior do partido" (grifos nossos).

Esta decisão do Poder Judiciário acabou por, de fato, estancar o fluxo da migração partidária. Mas, como efeito inesperado, criou um incentivo institucional à formação de novos partidos, pois este foi um dos caminhos autorizados para a migração partidária. Sugerimos, dessa forma, que a formação do PSD e de alguns outros novos partidos depois dele ocorre como uma espécie de equivalente funcional à migração partidária. As regras do jogo se alteraram, mas não sua lógica de funcionamento. Propriamente, uma lógica multinível entre o nacional e o local. Retornaremos a isso adiante.

O ponto a ser ressaltado aqui é que essa alteração de um dos incentivos institucionais essenciais de regulamentação da vida partidária no Brasil se deveu a decisôes e interpretações judiciais e não a deliberaçôes e decisões dos atores partidários, como presente nas teorias de formação de novos partidos.

I I Em maio de 2015, o STF, no julgamento da ADI (Ação Direta de Inconstitucionalidade) n 508I, restringiu a proibição aos eleitos pelo sistema proporcional, ou seja, vereadores e deputados estaduais e federais.

12 Resolução-TSE n²2.610, de 25.10.2007. http://www.tse.jus.br/legislacao/codigo-eleitoral/normas-editadas-pelo-tse/resolucao-nb0-22.610-de-25-de-outubro-de-2007-brasilia-20I3-df 
A importância do Judiciário ainda se manifesta em outras duas decisões, em junho de 2012, após a formação do PSD. Elas se referiram à distribuição do HGPE e do Fundo Partidário a novas legendas.

À época, a legislação vigente (Lei no 9.096/95) estabelecia as seguintes regras a respeito do Fundo Partidário, em seu art. 41-A:

Art. 4I-A. Do total do Fundo Partidário:

- 5\% (cinco por cento) do total do Fundo Partidário serão destacados para entrega, em partes iguais, a todos os partidos aptos que tenham seus estatutos registrados no Tribunal Superior Eleitoral;

- 95\% (noventa e cinco por cento) do total do Fundo Partidário serão distribuídos a eles na proporção dos votos obtidos na última eleição geral para a Câmara dos Deputados.

No que se refere ao HGPE, o art. 47, parágrafo segundo, terceiro e quarto da Lei no 9.504/97 estabeleciam que:

§ 2 Os horários reservados à propaganda de cada eleição, nos termos do parágrafo anterior, serão distribuídos entre todos os partidos e coligações que tenham candidato e representação na Câmara dos Deputados, observados os seguintes critérios:

I - um terço, igualitariamente;

II - dois terços, proporcionalmente ao número de representantes na Câmara dos Deputados, considerado, no caso de coligação, o resultado da soma do número de representantes de todos os partidos que a integram.

$\S 3^{\circ}$ Para efeito do disposto neste artigo, a representação de cada partido na Câmara dos Deputados é a resultante da eleição.

$\S 4^{\circ} \mathrm{O}$ número de representantes de partido que tenha resultado de fusão ou a que se tenha incorporado outro corresponderá à soma dos representantes que os partidos de origem possuíam na data mencionada no parágrafo anterior.

Os dois julgamentos, um no STF e outro no TSE, que favoreceram o PSD na distribuição do tempo de propaganda eleitoral gratuita e dos recursos do Fundo Partidário ocorreram na mesma data, 29 de junho de 2012, último dia antes do recesso de meio de ano do Judiciário. Em julho, os partidos realizariam suas convençóes para a definição de alianças e candidaturas com vistas à eleição municipal daquele ano. Tendo isso em conta, STF e TSE decidiram deliberar tempestivamente, isto é, antes do início de julho, a respeito de açóes que questionavam o regramento legal para distribuição do tempo de propaganda e do Fundo Partidário. 
No STF, a decisão favorável aos interesses do PSD foi suscitada pela ADI 4.795 ${ }^{13}$, apresentada pelo DEM, PMDB, PSDB, PPS, PR, PP e PTB. ${ }^{14}$ Nessa ADI, os partidos mencionados solicitavam ao STF que afastasse "[...] qualquer intelecção que (viesse) a estender às agremiaçóes político-partidárias que não elegeram representantes na Câmara dos Deputados o direito de participar do rateio proporcional de dois terços do tempo reservado à propaganda eleitoral gratuita no rádio e na TV”.

$\mathrm{O}$ relator da ADIs, ministro Dias Toffolli, apresentou voto contrário às demandas do PHS e do DEM, PMDB, PSDB, PPS, PR, PP e PTB. Toffoli consignou a interpretação de que os partidos fundados após a eleição parlamentar de 2010 poderiam participar da divisão proporcional de dois terços do tempo de propaganda levando em conta o número total de deputados federais que se filiaram ao partido quando de sua fundação. Luiz Fux, Rosa Weber, Ricardo Lewandowski, Gilmar Mendes, Celso de Mello e Ayres Britto acompanharam o voto do ministro Toffoli. A ministra Cármen Lúcia e os ministros Joaquim Barbosa, Cezar Peluso e Marco Aurélio Mello divergiram.

A decisão do STF deu ao PSD a possibilidade de contar com pelos menos 1 minuto e 59 segundos em cada bloco de 30 minutos no HGPE destinado às candidaturas próprias ou alianças para a eleição municipal de 2012 e para a eleição geral de 2014.

No TSE, a discussão foi a respeito da divisão dos recursos do Fundo Partidário. Neste caso, o próprio PSD suscitou a discussão por meio de uma petição (PET 174.793) encaminhada ao TSE em 16 de novembro de 2011. Na petição, o PSD solicitou que fosse incluído no grupo de partidos que tinham direito a dividir a parcela de $95 \%$ do Fundo Partidário tendo

I3 http://portal.stf.jus.br/processos/detalhe.asp?incidente=4257995.

14 No mesmo julgamento, estava em discussão outra ADI, a de número 4.430, apresentada pelo Partido Humanista da Solidariedade (PHS), na qual o partido solicitava aos ministros do STF decisão favorável a que o tempo de propaganda eleitoral fosse dividido igualitariamente entre todos os partidos que viessem a disputar a eleição municipal de 2012. O relator Dias Toffoli deu procedência parcial à demanda. Excluiu do $§ 2^{\circ}$ do art. 47 da Lei Eleitoral (Lei n 9.504/97) a expressão “e representação na Câmara dos Deputados”. Foi acompanhado pela maioria dos ministros do STF. Assim, a divisão igualitária de um terço do tempo de propaganda passou a valer para todos partidos e não apenas para os que tivessem representação na Câmara dos Deputados. Ao mesmo tempo, Toffoli sancionou a distribuição desigual de dois terços do tempo segundo o critério do tamanho proporcional das bancadas eleitas para a Câmara dos Deputados. 
como parâmetro os votos recebidos pelos partidos na eleição para a Câmara dos Deputados.

O processo foi distribuído inicialmente ao ministro Marcelo Ribeiro, que deu provimento à demanda do PSD. Além do relator, os ministros Marco Aurélio, Dias Toffoli e Nancy Andrighi votaram favoravelmente ao pleito. Já a então presidente do TSE, ministra Cármen Lúcia, e o ministro Arnaldo Versiani rejeitaram o pedido da legenda.

Em consequência dessa decisão favorável ao PSD, a parcela mensal que partido recebia do Fundo Partidário passou de R\$ 39.762,29, em agosto, para R\$2.244.420,98 em setembro. Em 2013, o PSD recebeu R\$ 17.619.266,53 $3^{15}$ provenientes do Fundo Partidário.

Assim, ressaltamos que as decisóes do Judiciário sobre o HGPE e sobre a distribuição do fundo público fortaleceram sobremaneira o PSD, e, dessa forma, criaram incentivos para outras empreitadas de formação de novos partidos.

\section{Os primeiros políticos do PSD}

Nesta seção, apresentaremos dados acerca do tamanho, da origem e do comportamento legislativo dos deputados fundadores do PSD, e do desempenho do partido nas eleiçóes de 2012 e 2014. As informaçóes serão analisadas tendo em vista a importância da relação entre os níveis nacional e local na conformação do partido, e seu comportamento legislativo como de uma agremiação que se situa na posição tipológica de Melo e Câmara (2012) como "à disposição".

\section{Deputados Federais}

No âmbito da Câmara Federal, o partido que mais forneceu quadros ao PSD foi o DEM. Dos 51 deputados fundadores do $\mathrm{PSD}^{16}$, 17 (33\%) vieram do antigo PFL. Os demais migraram de uma miríade de partidos, como mostra a Tabela 1 .

15 Em valores correntes.

I6 Adotamos como critério os parlamentares considerados como formadores do PSD pelo TSE e STF em suas decisões sobre o HGPE e o Fundo Partidário (TSE, 20I2). 
Um dos governadores do PSD, Raimundo Colombo, de Santa Catarina, também foi eleito pelo DEM, bem como a senadora Kátia Abreu (TO). Omar Azis, o outro governador pessedista era filiado ao PMN, mesmo partido do segundo senador do PSD, Sérgio Petecão (AC).

No entanto, a prominência do DEM com partido de origem dos parlamentares do PSD náo deve ocultar uma constataçáo igualmente relevante: a grande maioria, precisamente $77 \%$, dos deputados do partido conduzido por Kassab não migraram a partir dessa legenda. Além disso, se somarmos os políticos oriundos de agremiaçóes identificadas claramente com a oposição ao governo do PT (PSDB e PPS, além do DEM), não se chega à metade da bancada do Partido Social Democrático. Um dos parlamentares inclusive teve como origem o PT.

Tabela I - Partidos de origem de deputados federais

\begin{tabular}{cccccc}
\hline DEM & 17 & $33 \%$ & PP & 2 & $4 \%$ \\
PPS & 4 & $8 \%$ & PSDB & 2 & $4 \%$ \\
PR & 4 & $8 \%$ & PTB & 2 & $4 \%$ \\
PMDB & 4 & $8 \%$ & PCdoB & 1 & $2 \%$ \\
PV & 3 & $6 \%$ & PHS & 1 & $2 \%$ \\
PSC & 3 & $6 \%$ & PSB & 1 & $2 \%$ \\
PMN & 3 & $6 \%$ & PT & 1 & $2 \%$ \\
PDT & 3 & $6 \%$ & & & \\
\hline
\end{tabular}

Fonte: Câmara dos Deputados

Ou seja, é incorreto afirmar que se trata simples e cabalmente de um partido formado por antigos oposicionistas com intenção de se aproximar da coalizão de Dilma Rousseff. Outros determinantes parecem também importantes.

De forma a avançar a análise, o Gráfico 1 mostra a distribuição desses deputados por UF. Destaca-se o Amazonas, onde 37,5\% da bancada migrou para o PSD, e Goiás, Mato Grosso, Piauí e Tocantins, estados nos quais $20 \%$ ou mais dos deputados federais fundou o PSD. Na Bahia e em Santa Catarina, esse número alcançou pouco mais de $15 \%$. 
Gráfico I - Deputados federais fundadores PSD (\% bancada dos estados)

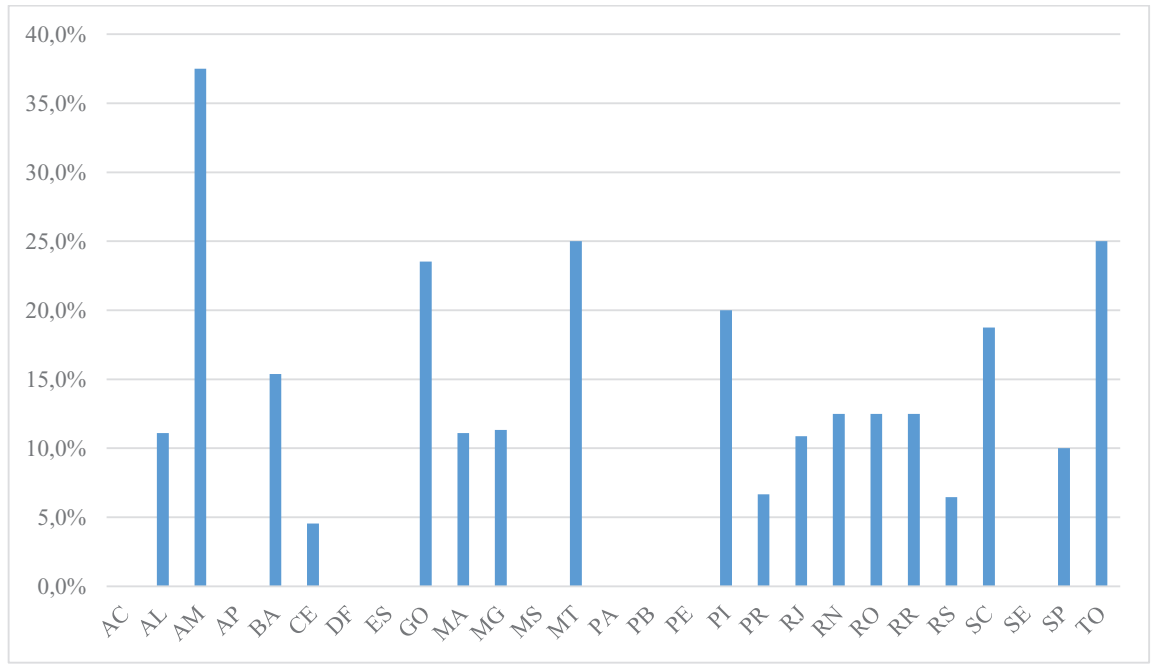

Fonte: Câmara dos Deputados

Considerando os estados nos quais o partido tinha governador ou vice-governador (SC, AM, SP, BA, TO, MT, RN, PB), a média da bancada federal filiada ao PSD era 18\%. Nas demais unidades da federação, era $7 \%$. Assim, tem-se uma relação clara entre penetração no executivo estadual e migração da bancada de deputados federais. Ou seja, mais um indício da lógica multinível na formação do partido.

Por fim, como forma de matizar o argumento de que a única lógica subjacente à criação do PSD foi a de aproximar políticos de oposição ao governo de Dilma Rousseff, particularmente em contextos regionais nos quais o PT era forte, cabe ressaltar que dos 17 deputados que se transferiram a partir DEM apenas seis eram de estados nordestinos.

\section{O comportamento dos deputados federais do PSD na Câmara dos Deputados}

Qual é o nível de apoio ao governo dos parlamentares fundadores do PSD nas votaçóes nominais da Câmara dos Deputados? Teria o PSD se alinhado no Congresso aos interesses do Executivo? A incorporação ao 
governo por meio de uma secretaria com status de ministério alterou o comportamento da bancada do PSD?

Para realizar essa análise, consideramos dados de apoio ao governo em votaçóes nominais na Câmara dos Deputados ${ }^{17}$. Dividimos a análise em três períodos: (I) do começo de 2011 até a fundação do PSD, em setembro de 2011; (II) de setembro de 2011 ao ingresso do PSD na base do governo, por meio da nomeação de Afif Domingos, em maio de 2013; e (III) de maio de 2013 até dezembro de $2014^{18}$.

Para efeito de precisar as evidências, procedemos a uma comparação do comportamento do PSD com o apoio que o governo obteve da sua coalizão e dos três principais partidos brasileiros: PT, PSDB e PMDB. Como a maioria dos políticos constituintes do PSD foi proveniente do DEM, este partido também será levado em conta na análise comparativa. O gráfico 2, a seguir, apresenta os dados.

Gráfico 2 - \% de apoio ao governo de deputados federais presentes na votação

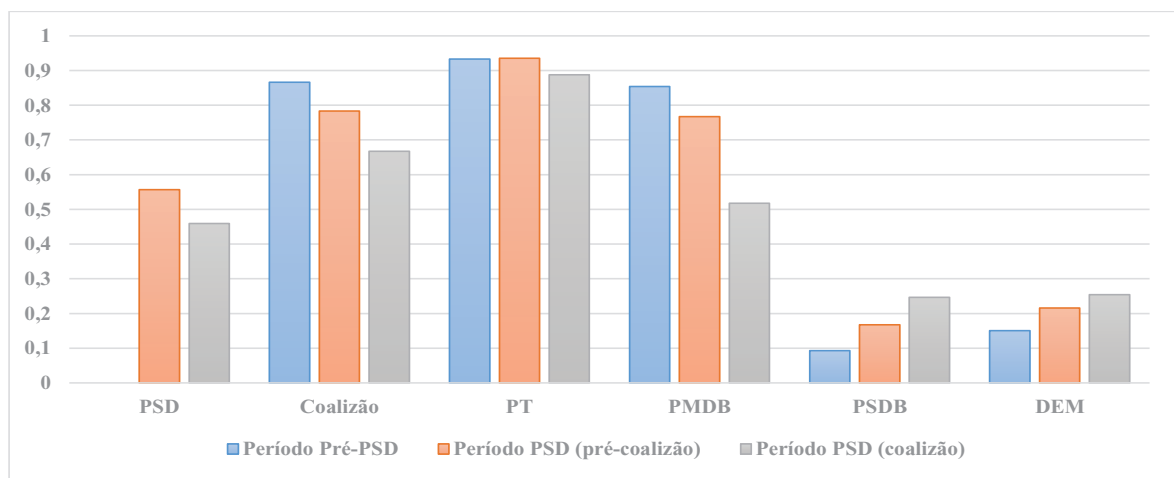

Fonte: Banco de Dados Legislativos do CEBRAP

Os resultados mostram que o apoio geral que o governo obteve na Câmara dos Deputados declinou com o passar do tempo. A disciplina

17 Utilizamos o Banco de Dados Legislativo do Cebrap. Consideramos todas as deliberações de qualquer matéria (projeto de lei, proposta de emenda constitucional, medida provisória, destaques etc.) em plenário que ocorreram por votação nominal, que foram válidas e não unânimes (seguindo o critério de Figueiredo e Limongi, 1999), e que tiveram indicação de voto do líder do governo.

18 O número de votações em cada período foi: 31, 51 e 73, respectivamente. 
da coalizão passou de $87 \%$ no período anterior à formação do PSD, para $78 \%$ no período seguinte e chegou a $67 \%$ entre maio de 2013 e o final da legislatura. São notáveis as diferenças internas à coalizão: enquanto o PT apresentou apenas uma leve queda, o PMDB despencou de $85 \%$ a $52 \%$.

Os partidos da oposição tiveram comportamento inverso: aumentaram seu apoio com o correr dos três períodos. O PSD, por sua vez, no período anterior à sua entrada na coalizão apoiou o governo em média na ordem de 55\%. Acompanhando os movimentos da coalizáo, o partido apresentou uma queda após seu ingresso no gabinete, apoiando o governo em 46\% em média.

Para melhor compressão do comportamento do partido, procedemos a uma desagregaçáo dos parlamentares do PSD em três grupos de acordo com o partido de origem: (1) os que se transferiram de partidos da base do governo (PR, PP, PMDB, PDT, PCdoB, PSB); (2) os que tiveram origem na oposição (DEM, PPS e PSDB) e (3) aqueles que anteriormente pertenciam a partidos que podemos chamar de satélites (PTB, PMN, PSC, PV, PHS e PSL), que são partidos pequenos (à exceção do PTB), que muitas vezes apoiam o governo mesmo sem possuir pastas ministeriais. Observamos o comportamento em relaçáo ao governo desses três grupos, nos três períodos delimitados. Essa estratégia analítica permite verificar o impacto da formação do PSD no comportamento legislativo dos parlamentares. Os resultados são os seguintes: 
Gráfico 3 - \% de apoio ao governo de deputados federais presentes na votação - PSD, de acordo com origem

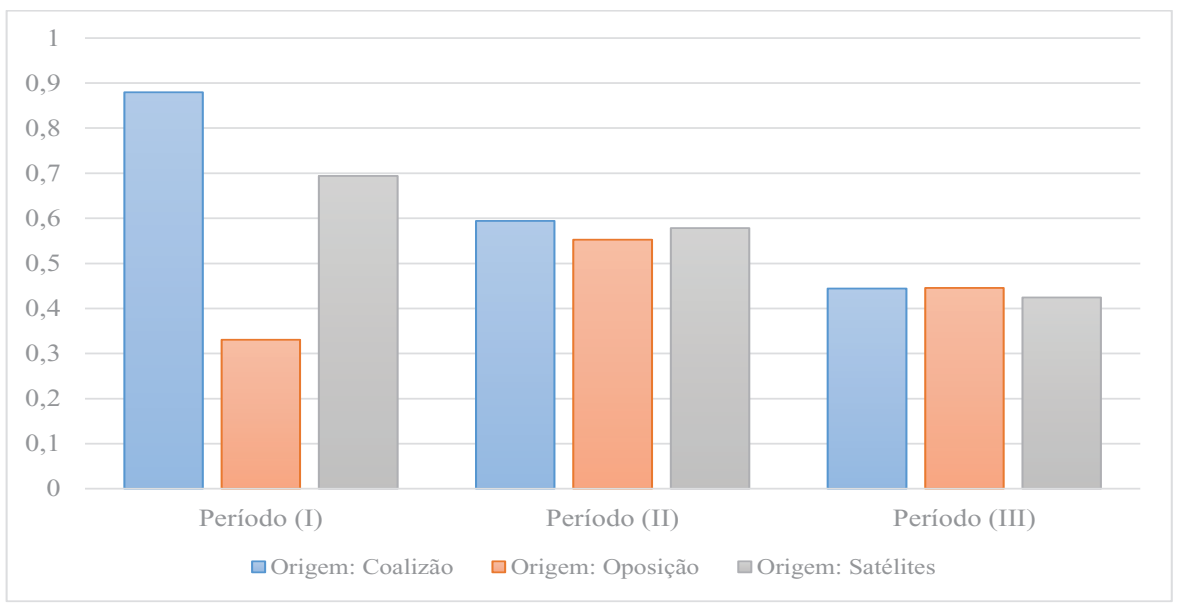

Fonte: Banco de Dados Legislativos do CEBRAP

Salta aos olhos o processo de similaridade no comportamento legislativo que ocorre nos três grupos a partir do momento da formação do PSD. E o mais interessante: esse processo ocorreu tanto por meio do aumento da taxa de apoio do grupo cuja origem são os partidos da oposição, como também por meio da diminuição da taxa de apoio dos deputados que se transferiram de partidos da base do governo e de partidos satélites.

Duas conclusóes podemos tirar desses resultados. A primeira conclusão é que observamos o processo de criação efetiva de um partido, onde as diferenças de origem no comportamento de seus parlamentares foram minimizadas. Isso se choca com a ideia de que partidos no Brasil são entidades fluidas. A segunda conclusão que deve ser matizada é a afirmação de que o PSD representa simplesmente um movimento em direçáo ao governo federal. O partido sempre apresentou níveis de apoio inferiores aos da coalizão, e considerando o grupo heterogêneo que o formou, o resultado líquido dos movimentos que garantiram a coesão partidária acabou por diminuir o apoio obtido pelo governo. 
Reforça-se, assim, a tese de que o PSD se constitui como um partido "à disposição", na caracterização elaborada por Melo e Câmara (2012), e que diversos fatores estiveram presentes na determinaçáo de sua formação.

\section{Prefeitos e vereadores}

O PSD estreou com relativo sucesso nas urnas em 2012. Elegeu 4.664 vereadores e 497 prefeitos, sendo um deles em uma capital de estado (Florianópolis). Considerando o número de prefeitos, tornou-se o quarto maior partido brasileiro, atrás apenas do PMDB, PSDB e PT

Em termos absolutos, a Bahia foi o estado que mais contribuiu para esse total, com 70 prefeitos e 553 vereadores eleitos. Há destaque também para Santa Catarina, com 54 prefeitos e 489 vereadores. Em termos relativos, contudo, como mostra o gráfico 4 a seguir, o Amazonas e o Mato Grosso se sobressaem: o PSD venceu a eleição em quase $40 \%$ do total de municípios amazonenses e conquistou mais de $28 \%$ das cadeiras legislativas municipais no estado da região centro-oeste.

Gráfico 4 - \% de vereadores e prefeitos eleitos - PSD (2012)

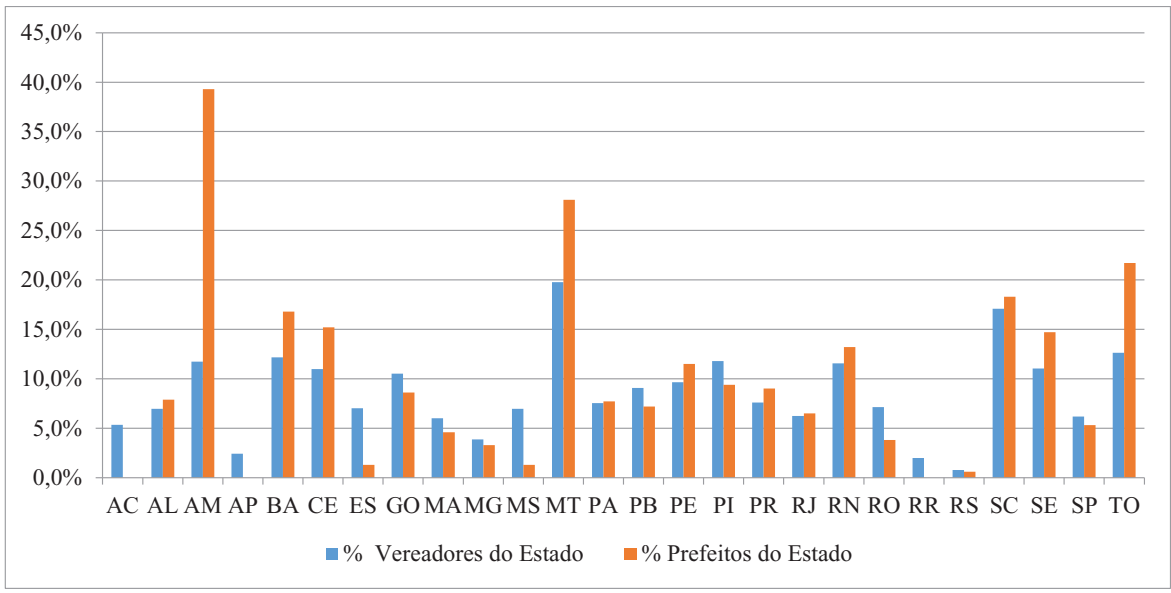

Fonte: TSE

O desempenho do partido foi ainda melhor nos estados cujo governador ou vice pertenciam ao PSD. No âmbito das prefeituras, a legenda saiu 
vencedora em $18,7 \%$ das cidades e conquistou $12,5 \%$ das cadeiras de vereador. Nos demais estados, elegeu 5,9\% dos prefeitos e 6,9\% dos vereadores.

Ou seja, a mesma relação entre níveis que identificamos no caso de deputados federais se aplica aos cargos municipais. Mais do que isso, Krause e Gerardi (2014) mostram que o mesmo padrão ocorre com os prefeitos que migraram para o PSD em 2011. Além disso, os autores também ressaltam que a saída de mandatários municipais do DEM em direção ao PSD se deu mais fortemente no Sul e Sudeste e menos no Nordeste, o que mais uma vez matiza a tese do governismo em regióes lulistas.

\section{O PSD na eleição de 2014}

O PSD conseguiu eleger dois governadores em 2014. Raimundo Colombo foi reeleito em Santa Catarina no primeiro turno com 51,3\% dos votos. Robinson de Faria venceu no Rio Grande do Norte no segundo turno com 54,4\% dos votos. Assim, o PSD logrou manter o comando do governo de dois estados. Trocou o Amazonas pelo Rio Grande do Norte e continuou com Santa Catarina.

Além de Colombo e Faria, o PSD lançou mais dois candidatos a governador em 2014. Foram Luiz Cantuária Barreto (AP) e Janete Gomes Riva (MT). Ambos ficaram em terceiro lugar. O fato de o PSD ter lançado apenas quatro candidatos a governador, apesar de ter nascido como um dos principais partidos do país, reforça o diagnóstico da literatura a respeito da especialização dos partidos brasileiros. PT e PSDB privilegiam a eleição presidencial. PMDB investe nas eleiçôes estaduais e legislativas. O PSD, por sua vez, mostrou na sua primeira eleição nacional que o principal foco do partido era a eleição parlamentar.

Impossibilitado de disputar a reeleição, Omar Aziz (AM), o outro governador além de Colombo que aderiu ao PSD quando de sua fundação, candidatou-se ao Senado. Foi eleito com 58,5\% dos votos válidos. O segundo senador eleito foi Otto Alencar (BA), que ocupava o cargo de vice-governador do estado antes de se desincompatibilizar do cargo para tentar chegar ao Senado. Com Aziz, Alencar e Sérgio Petecão (AC), cujo mandato terminaria apenas em 2018, o PSD conseguiu manter três cadeiras no Senado. 
O PSD elegeu 36 deputados federais em 2014. Sendo assim, perdeu 15 cadeiras na Câmara dos Deputados, considerando o tamanho da primeira bancada do partido formada a partir da migração de parlamentares de outras legendas para o PSD. O PSD perdeu mais deputados federais em Minas Gerais e em São Paulo, três em cada um deles. Mas as perdas foram desconcentradas nos estados. Em nenhum ente federativo houve queda acentuada.

O índice de correlação entre o peso percentual estadual dos deputados federais fundadores e dos eleitos em 2014 é de 0,43 , valor relativamente baixo. Isso mostra alguma descontinuidade entre a organização do partido feita quando da fundação da legenda e o resultado obtido na primeira eleição nacional na qual o PSD participou. Mesmo assim, cabe ressaltar que o PSD conseguiu melhores resultados em Santa Catarina e no Amazonas, justamente os estados de seus dois primeiros governadores.

Em termos absolutos, o Rio de Janeiro foi o estado que mais elegeu deputados federais pessedistas. Foram seis. Em termos relativos, considerando o tamanho das bancadas em cada estado, os destaques foram Amazonas, onde o PSD conseguiu conquistar 25\% das cadeiras estaduais, e Santa Catarina $(18,8 \%)$.

O PSD elegeu também 75 deputados estaduais, 7,1\% do total de cadeiras disponíveis em Assembleias Legislativas no país, percentual muito próximo ao alcançado na Câmara dos Deputados (7,0\%). Santa Catarina foi o estado no qual o PSD conseguiu o melhor desempenho na eleição para deputado estadual, tanto em termos absolutos como relativos. O PSD conquistou nove cadeiras na Assembleia Legislativa de Santa Catarina (22,5\% do total). Em seguida, vieram Bahia (oito cadeiras, $12,7 \%$ do total) e Amazonas (três cadeiras, $12,5 \%$ do total).

O gráfico 5 a seguir mostra o desempenho relativo do PSD nas eleiçóes para deputado federal e estadual em cada estado. $\mathrm{O}$ índice de correlação entre as duas variáveis é de 0,54 . 


\section{Gráfico 5 - Deputados federais e estaduais eleitos pelo PSD em 2014 (\% bancada dos estados)}

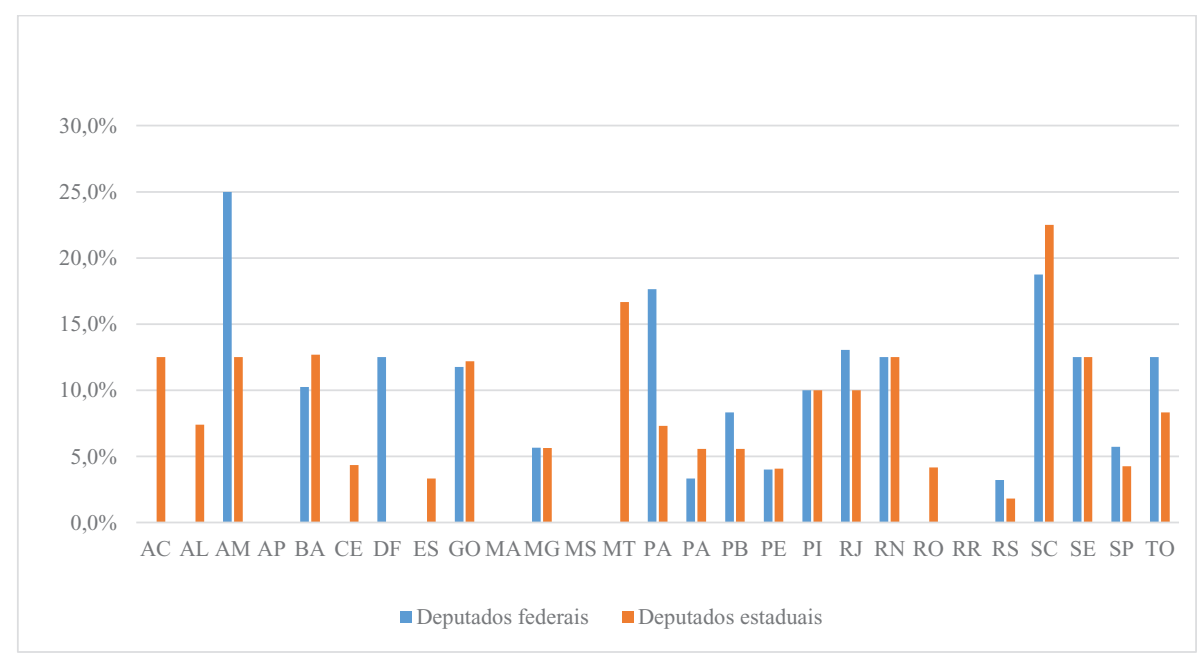

Fonte: TSE

Os estados de desempenho mais positivo tanto na eleição para deputado federal quanto estadual foram Santa Catarina (2० no ranking de deputados federal e $1^{\circ}$ no de deputados estaduais), Amazonas ( $1^{\circ}$ e $5^{\circ}$, respectivamente) e Rio Grande do Norte (6 $6^{\circ} \mathrm{em}$ ambos).

Nesses três estados, o PSD obteve resultados positivos nas eleiçóes para governador e para o Senado. Fez os governadores de Santa Catarina e do Rio Grande do Norte. No Amazonas, elegeu o senador Omar Aziz, que até abril daquele ano era governador do estado. São informaçôes que reforçam a ideia da lógica multinível do PSD.

No que diz respeito às coalizóes na eleição para governador, se considerarmos o conjunto dos estados, não é possível destacar um aliado preferencial para o PSD. Entre as legendas relevantes, as que participaram com mais frequência de coalizóes ao lado do PSD foram PSDB (14 estados), PP, PR e PPS (13 estados), PMDB (12 estados) e DEM (11 estados).

Levando em conta os estados nos quais o PSD lançou candidato próprio a governador (SC, RN, AP e MT), tampouco é possível indicar um 
aliado preferencial. Neste caso, a dispersão de parcerias é ainda mais ampla. Nenhum partido apoiou candidatos a governador pelo PSD em mais de dois estados.

Contudo, há dois nítidos aliados mais usuais quando a perspectiva é inversa, ou seja, quando o PSD apoiou candidatos a governador de outras legendas. Neste caso, dois partidos se sobressaem: PSDB e PMDB. O PSD apoiou oito candidatos a governador de cada um desses partidos e apenas quatro do PSB, dois do PT e um do PROS.

Vale notar que o PSD compôs a coligação da candidata a presidente petista, Dilma Rousseff, a lado de PMDB, PDT, PC do B, PP, PR, PROS, $\mathrm{PRB}$ e, claro, do próprio PT. O PT, no entanto, não foi aliado frequente do PSD nos estados. Somente dois candidatos petistas a governador foram apoiados pelo PSD: Camilo Santana (CE) e Rui Costa (BA). Por outro lado, Robinson de Faria (RN) foi o único candidato a governador do PSD apoiado pelo PT. ${ }^{19}$ Além disso, no geral, o PT esteve junto com o PSD em apenas sete estados. As informaçóes sobre a participação do PSD em coalizóes nas disputas para o governo de estado estão na tabela 2 a seguir.

A heterogeneidade das coligaçóes nas quais o PSD participou e, principalmente, o fato de o partido ter se aliado ao PT na eleição presidencial e apoiado o PSDB em oito estados reforça a condição do PSD como um "partido disponível”, usando a terminologia de Melo e Câmara (2012).

I9 Note-se que todos esses candidatos (Rousseff, Santana, Costa e Faria) foram eleitos. 
Tabela 2 - Coalizões entre o PSD e demais partidos na eleição para governador em 2014

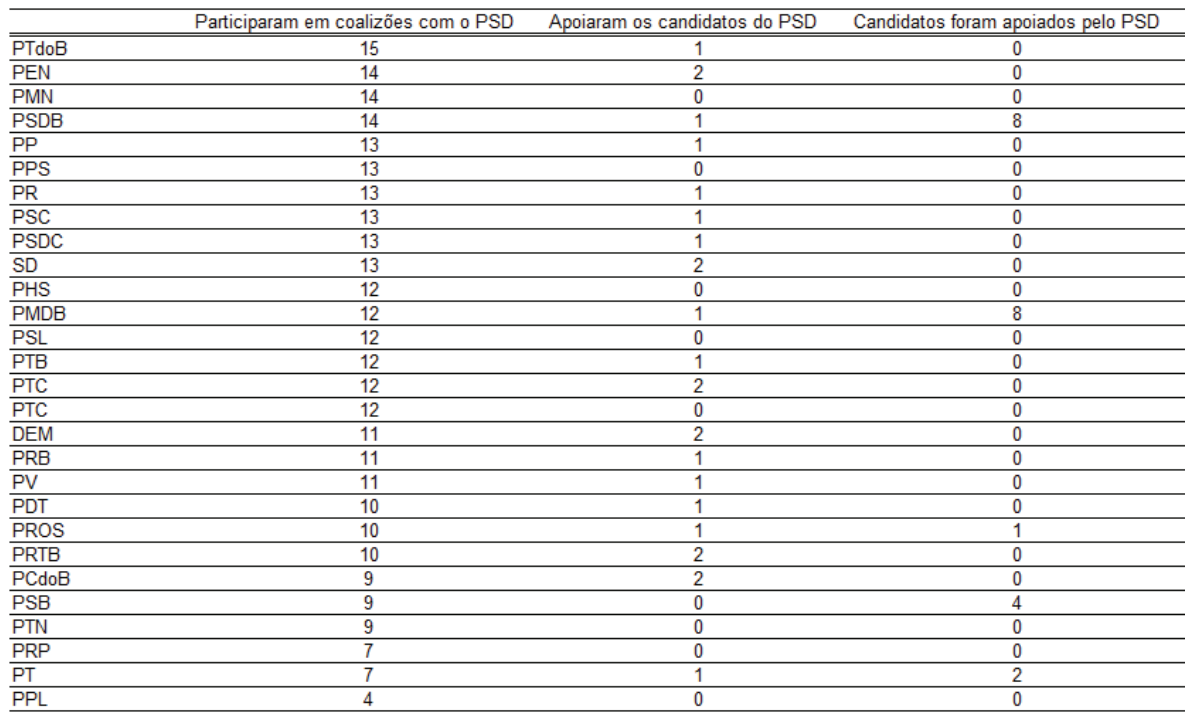

Fonte: TSE

\section{Considerações finais}

O debate sobre a estrutura do quadro partidário anima a Ciência Política brasileira. Neste artigo, buscamos contribuir para a literatura levantando dados e elementos analíticos sobre a fundação e relevância de um novo partido, o PSD, normalmente visto como expressão da fragilidade e fragmentação do sistema partidário, e da tendência de atração centrípeta emanada do Executivo federal.

A argumentação que apresentamos busca ressaltar que um entendimento adequado sobre a formação e o papel exercido por este novo partido relevante deve se apoiar também em outras lógicas. Particularmente, a interferência do Poder Judiciário nas regras da competição partidário-eleitoral e a importância da coordenação multinível no sistema partidário brasileiro.

Defendemos que a formação do PSD, e de outros partidos novos relevantes, deve ser compreendida à luz da interdição da migração partidária efetuada pelas Cortes brasileiras. Ao buscar coibir esse comportamento, 
STF e TSE determinaram que uma das justas causas para mudança de partido é a formação de nova legenda, incentivando, como consequência não esperada, a proliferação de novos partidos. O Poder Judiciário também teve importância central ao determinar que o HGPE e o Fundo Partidário fossem distribuídos aos novos partidos de acordo com o número de parlamentares fundadores, mesmo estes sendo eleitos por outras legendas. Assim, as elites políticas tiveram de se adaptar às mudanças institucionais exogenamente determinadas, variável essa desconsiderada nas teorias sobre formação de novos partidos.

Mas qual é a lógica que movimenta essas elites políticas? Defendemos neste artigo que, antes que demonstrar a impertinência das interpretaçóes sobre o sistema partidário que ressaltam estruturas estáveis de competição e coordenação, o processo de formação do PSD somente é possível de ser compreendido adequadamente se lançarmos mão dessa perspectiva, ainda que não sem alguns refinamentos.

Em sistema presidencialista multipartidário e federativo como o brasileiro, os partidos estão envolvidos em um sistema de competição extremamente complexo, com ampla extensão territorial, diversos níveis de competição e regras eleitorais. Nesse cenário, é racional que as legendas desenvolvam estratégias de "especialização" em determinados cargos e níveis de competição. Alguns partidos buscam, por exemplo, maximizar bancadas legislativas, as quais são um ativo importante no funcionamento do presidencialismo de coalizão.

O ponto que nos interessa ressaltar é que, visto que os parlamentares federais são eleitos em distritos estaduais, o sistema partidário brasileiro tem fortes componentes multiníveis, ou seja, de determinação recíproca entre os níveis nacionais e locais do sistema partidário. Essa lógica foi utilizada para explicar a migraçáo partidária e, semelhantemente, apresentamos uma série de dados que indicam que no PSD existe um fenômeno semelhante.

Dessa forma, ressaltamos que a disputa pelo poder dentro do DEM e o desejo de parte da oposiçáo a de se aproximar do governo federal não são causas suficientes para explicar a formação e principalmente a força do PSD. Também devem ser levadas em consideração estruturas gerais do sistema político brasileiro, estruturas estas que também permitem seu funcionamento estável. 


\section{Referências}

ALDRICH, J. Why Parties? The origin and transformation of political parties in America. Chicago: The University of Chicago Press. 1995.

AVELINO, G. Reforma Política: Brasil, o maior NEP do mundo! 2015. Disponível em: https:// cepesp.wordpress.com/2015/05/13/reforma-politica-brasil-o-maior-nep-do-mundo/. Acesso em: 20 nov. 2018.

BATES, R. H.; GREIF, A.; LEVI, M.; ROSENTHAL, J-L. Analytic Narratives. Princeton: Princeton University Press. 1998.

BRAGA, M. Eleições e democracia no Brasil: a caminho de partidos e sistema partidário institucionalizados. Revista Brasileira de Ciência Política, Brasília, n. 4, p. 43-73, jul./dez. 2010.

CARREIRÃO, Y. O sistema partidário brasileiro: um debate com a literatura recente. Revista Brasileira de Ciência Política, n. 14. p. 255-295, maio/ago. 2014.

CARREIRÁO, Y e KINZO, M. D. Partidos políticos, preferência partidária e decisão eleitoral no Brasil (1989/2002). Dados. v. 47, n. 1, p.131-167, 2004.

CHHIBBER, P. e KOLLMAN. K. The Formation of National Party Systems: Federalism and Party Competition in Canada, Great Britain, India, and the United States. Princeton: Princeton University Press. 2004.

CORTEZ, R. Eleiçóes majoritárias e entrada estratégica no sistema partidário eleitoral brasileiro. Tese de doutorado em Ciência Política. Doutorado (Doutorado em Ciência Política). Universidade de São Paulo, 2009.

COX, G. Making Votes Count: Strategic Coordination in the World's Electoral Systems. Cambridge: Cambridge University Press. 1997.

DESPOSATO, S. Parties for rent? Ambition, ideology and party-switching in Brazil's Chamber of Deputies. American Journal of Political Science, v. 50, n. 1, p.62-80, 2006.

DOSEK, T.; FREIDENBERG, F. La congruencia de los partidos y los sistemas de partidos multinivel em América Latina: conceptualización y evaluación de algunas herramienatas de medición. Politai: Revista de Ciencia Política, Ano 4, n. 7, p. 161-178, 2013.

FIGUEIREDO, A.; LIMONGI, F. Executivo e Legislativo na Nova Ordem Constitucional. Rio de Janeiro: Ed. FGV. 1999.

FREITAS, A. Migração partidária na Câmara dos Deputados de 1987 a 2009. Dados, v. 55, n. 4. p. 951-986, 2012.

HARMEL, R.; ROBERTSON, J. Formation and Success of New Parties. International Political Science Review, v. 6: p. 501-523, 1985.

HUG, S. Studying the Electoral Success of New Political Parties: A Methodological Note. Party Politics, v. 6, n. 187, p. 187-197, 2000. 
KINZO, M. D. Partidos, eleiçôes e democracia no Brasil pós-1985. Revista Brasileira de Ciências Sociais, v. 19, n. 54, p. 23-40, 2004.

KRAUSE, S.; GERARDI, D. A. Executivo estadual faz diferença? A estreia eleitoral do PSD nas eleiçōes municipais de 2012. Paper apresentado no IX Encontro da ABCP. 2014.

LAGO, I.; MARTÍNEZ, F. Why new parties? Party Politics, v. 17, n. 1, p. 3-20, 2011.

LAGO, I.; MONTERO, J. R. Coordination between electoral arenas in multilevel countries. European Journal of Political Research, v. 48, issue 2, p. 176-203, 2009.

LIMONGI, F.; CORTEZ, R. As eleições de 2010 e o quadro partidário. Novos Estudos Cebrap, n. 88 , p. $21-37,2010$.

LIMONGI, F.; VASSELAI, F. Entries and Withdrawals: Electoral Coordination across Different Offices and the Brazilian Party Systems. Brazilian Political Science Review, vol.12, n.3, 2018.

MAINWARING, S. Rethinking Party Systems in the Third Wave of Democratization: The Case of Brazil. Stanford University Press. 1999.

MAINWARING, S.; TORCAL, M. Teoria e institucionalização dos sistemas partidários após a terceira onda de democratização. Opiniáo Pública, v.11, n. 2, p. 249-286, 2005.

MARCHETTI, V. Governança eleitoral: o modelo brasileiro de justiça eleitoral. Dados, v. 51, n. 4, p. 865-893, 2008.

MELO, C. R. Partidos e Migração Partidária na Câmara dos Deputados. Dados, v. 43, n. 2, 2000.

MELO, C. R. Eleiçôes Presidenciais, jogos aninhados e sistema partidário no Brasil. Revista Brasileira de Ciência Política, n. 4, p.13-41, 2010.

MELO, C. R.; CÂMARA, R. Estrutura da Competição pela Presidência e Consolidação do Sistema Partidário no Brasil. Dados, v. 55, n. 1, p. 71-117, 2012.

NERI, M. A Nova Classe Média: o lado brilhante da base da pirâmide. São Paulo: Saraiva. 2010.

NICOLAU, J. Partidos e sistemas partidários: 1985-2009. In: MARTINS, C. B.; LESSA, R. (Org.) Horizontes das Ciências Sociais no Brasil: Ciência Política. São Paulo, 2010.

NICOLAU, J.; SCHMITT, R. Sistema eleitoral e sistema partidário. Lua Nova, n. 36, p. 129-147. 1995.

O ESTADO DE S. PAULO, 17 nov. 2010, pg A9. https://acervo.estadao.com.br/ pagina/\#!/20101117-42764-nac-9-pol-a9-not

O ESTADO DE S. PAULO, 29 mar. 2011. https://acervo.estadao.com.br/ pagina/\#!/20110329-42896-nac-7-pol-a7-not.

PANEBIANCO, A. Modelos de partidos. São Paulo: Martins Fontes, 2005.

POGUNTKE, T. New politics and party systems: The emergence of a new type of party? West European Politics, v. 10, n.1, p. 76-88, 1987. 
RIBEIRO, R. Decadência longe do poder: refundação e crise do PFL. Revista de Sociologia e Política, v. 22, n. 49, jan./mar 2014.

SAMUELS, D. Ambition, federalism, and legislative politics in Brazil. Cambridge: Cambridge University Press, 2003.

SAMUELS, D.; SHUGART, M. Presidents, Parties, and Prime Ministers: How the Separation of Powers Affects Party Organization and Behavior. Cambridge: Cambridge University Press, 2016.

SIKK, A. Newness as a winning formula for new political parties. Party Politics, v. 18, n; 4, p. $465-486,2012$.

SILVA, A.; SANTOS, P. O princípio da fidelidade partidária e a possibilidade de perda de mandato por sua violação - Uma análise segundo a jurisprudência do Supremo Tribunal Federal. Revista do Instituto de Hermenêutica Jurídica, n. 14, p. 13-34, jul./dez. 2013.

SU, Y. P. Party registration rules and party systems in Latin America. Party Politics, v. 21, n. 2, p. 295-308, 2015.

SUPREMO TRIBUNAL FEDERAL. Resolução no 22.610, 25 out. 2007.

TAVITS, M. Party System Change, Party Politics, v. 12, p. 99-119, 2006.

TRIBUNAL SUPERIROR ELEITORAL. TSE fixa bancada de deputados federais para cálculo do tempo de propaganda. 9 ago. 2012. Disponível em: http://www.tse.jus.br/imprensa/noticiastse/2012/Agosto/tse-fixa-bancada-de-deputados-federais-para-calculo-do-tempo-de-propaganda.

\section{The emergence of PSD and the Brazilian party system}

What does explain the resurgence of new relevant political parties in Brazil? How is it related to the institutionalization of party system or the structure of electoral competition? We address this issue through the of analysis of PSD (Partido Social Democrata). We expose its historical formation process, highlighting actors, strategies and conjunctures; we analyze the legislative behavior of deputies that have moved to PSD in Lower Chamber and we explore its electoral performance in 2012 and 2014, stressing the PSD strategic entry and its local electoral bases. We argue that both the federal and local structure party competition are connected to the formation and strength of PSD. Furthermore, we argue that some decisions of Judiciary Branch related to electoral and party legislation, a variable that is not included in comparative theories of new relevant party formation, are also central to this phenomenon.

Keywords: political party; party system institutionalization; new parties; multilevel party system.

Recebido em 26/11/2018

Aprovado em 20/05/2019 